ВІСНИК

ОДЕСЬКОГО НАЦІОНАЛЬНОГО

МОРСЬКОГО УНІВЕРСИТЕТУ

№ 1 (61), 2020
HERALD

OF THE ODESSA NATIONAL

MARITIME UNIVERSITY № 1 (61), 2020

УДК 627.51

DOI 10.47049/2226-1893-2020-1-167-179

\title{
СПОСОБ ВОЗВЕДЕНИЯ УНИВЕРСАЛЬНОГО МОРСКОГО ГИДРОТЕХНИЧЕСКОГО СООРУЖЕНИЯ
}

\author{
С.И. Рогачко \\ д.т.н., профессор, профессор кафедры \\ «Морские и речные порты, водные пути и их техническая эксплуатация» \\ А.В. Слободяник \\ к.т.н., старший преподаватель кафедры \\ «Морские и речные порты, водные пути и их техническая эксплуатация» \\ Одесский национальный морской университет, Одесса, Украина
}

Аннотация. Морские берега Украины в Черном и Азовском морях, на лиманах, озерах и водохранилищах подвергаются интенсивному разрушению ветровыми волнами и дрейфующими ровными ледяными полями. Наступление водоемов на берега приводит к существенным невозвратнымм потерям сельскохозяйственных площадей и другим материальным убыткам. Многие населенные пункты, расположенные на берегах в течение нескольких десятилетий потеряли иелые улииы вместе с построенными на них домами и другими постройками. Известны случаи выпора ровных ледяных полей под воздействием сил дрейфа на пологие берега. При этом были разрушены все береговые объекты на них расположенные. Избежать таких неблагоприятных явлений можно только строительством берегозащитных сооружений, способных успешно противостоять силовому воздействию ветровых волн и дрейфующих ровных ледяных полей. Строительство берегозащитных сооружений особенно необходимо в местах расположения населенных пунктов и городов.

В настоящее время Украина, несмотря на наличие перспективных на разработку месторождений углеводородов, как на суше, так и на шельфе Черного моря, является энергозависимой страной. По этой причине обустройство разведанных месторождений углеводородов, в первую очередь на мелководных участках шельфа, представляется важнейшей народнохозяйственной задачей. Решение этой задачи в нашей стране собственными силами требует строительства морских нефтегазопромысловых гидротехнических сооружений в виде искусственных островов.

Успешное решение перечисленных проблем всечело зависит от разработки прогрессивных методов возведения гидротехнических сооружений (как берегозащитных, так и морских нефтегазопромысловых) в условиях открытого моря.

(С) Рогачко С.И., Слободяник А.В., 2020 
ВІСНИК

ОДЕСЬКОГО НАЦІОНАЛЬНОГО

МОРСЬКОГО УНІВЕРСИТЕТУ
HERALD

OF THE ODESSA NATIONAL

MARITIME UNIVERSITY № 1 (61), 2020

В настоящей работе изложен, разработанный авторами статьи, инновачионный способ возведения гидротехнических сооружений различного назначения при минимальном использовании ручного труда водолазов.

Ключевые слова: берегозащитное сооружение, лицевая плита, опорная рама, свая, внешние нагрузки.

УДК 627.51

DOI 10.47049/2226-1893-2020-1-167-179

\section{СПОСІБ ЗВЕДЕННЯ УНІВЕРСАЛЬНОЇ МОРСЬКОЇ ГІДРОТЕХНІЧНОЇ СПОРУДИ}

\section{C.I. Рогачко}

д.т.н., професор, професор кафедри

«Морські і річкові порти, водні шляхи та їх технічна експлуатація»

\section{Г.В. Слободяник}

к.т.н., старший викладач кафедри

«Морські і річкові порти, водні шляхи та їх технічна експлуатація»

Одеський наџіональний морський університет, Одеса, Украӥна

Анотація. Морські береги України в Чорному та Азовському морях, на лиманах, озерах $i$ водосховищах піддаються інтенсивному руйнуванню вітровими хвилями $i$ дрейфуючими рівними крижаними полями. Наступ водойм на береги призводить до суттєвих безповоротних втрат сільськогосподарських площ і інших матеріальних збитків. Багато населених пунктів, які розташовані на берегах протягом декількох десятиліть втратили цілі вулиці разом з побудованими на них будинками та іншими будівлями. Відомі випадки випору рівних крижаних полів під впливом сил дрейфу на пологі береги. При цьому були зруйновані всі берегові об'єкти, що на них розташовані. Уникнути таких несприятливих явищ можна тільки за допомогою будівництва берегозахисних споруд, здатних успішно протистояти силовому впливу вітрових хвиль $i$ дрейфуючих рівних крижаних полів. Будівництво берегозахисних споруд особливо необхідно в місиях розтамування населених пунктів $і$ міст.

В даний час Украӥна, незважаючи на наявність перспективних на розробку родовищ вуглеводнів, як на суші, так і на шельфі Чорного моря, $\epsilon$ енергозалежною краӥною. 3 иієї причини облаштування розвіданих родовищ вуглеводнів, в першу чергу на мілководних ділянках шельфу, $\epsilon$ найважливішим народногосподарським завданням. Вирішення иього завдання в нашій краӥні власними силами вимагає будівництва морських нафтогазопромислових гідротехнічних споруд у вигляді штучних островів. 
Успішне вирішення перерахованих проблем цілком залежить від розробки прогресивних методів зведення гідротехнічних споруд (як берегозахисних, так $i$ морських нафтогазопромислових) в умовах відкритого моря. У даній роботі викладено, розроблений авторами статті, інноваційний спосіб зведення гідротехнічних споруд різного призначення при мінімальному використанні ручної праці водолазів.

Ключові слова: берегозахисна споруда, лищьова плита, опорна рама, паля, зовнішні навантаження.

UDC 627.51

DOI 10.47049/2226-1893-2020-1-167-179

\title{
THE METHOD OF CONSTRUCTION OF AN UNIVERSAL MARINE HYDRAULIC STRUCTURES
}

\author{
S. Rogachko \\ doctor of engineering, professor, of the Department \\ «Marine and river ports, waterways and its technical service» \\ H. Slobodianyk \\ candidate of engineering science, of the Department \\ «Marine and river ports, waterways and its technical service» \\ Odessa National Maritime University, Odessa, Ukraine
}

\begin{abstract}
Sea shores of Black Sea and Azov Sea, banks of estuaries, lakes and reservoirs in Ukraine are subjected to intensive destruction by wind waves and drifting level ice. The onset of water on the coast leads to significant irretrievable losses of agricultural land and other material losses. For many decades, settlements located on the shores have lost entire streets along with houses built on them and other buildings. It is known, that there are cases of overburden of level ice under the influence of drift forces on gentle shores. In this case, all coastal facilities located on them were destroyed. Such adverse events can only be avoided by building coastal protection structures capable of successfully resisting the forceful effects of wind waves and drifting level ice. The construction of shore protection structures is especially necessary in the locations of settlements and cities.

At present, Ukraine, despite the presence of promising hydrocarbon deposits both on land and on the shelf of the Black Sea, is an energy-dependent country. For this reason, the development of explored hydrocarbon deposits, primarily in the shallow areas of the shelf, seems to be the most important economic task. Solving this task in our country on our own requires the construction of offshore oil and gas hydraulic structures in the form of artificial islands.

The successful solution of these problems depends entirely on the development of progressive methods of construction hydraulic structures (both
\end{abstract}


shore protection and offshore oil and gas fields) in the open sea. Innovative method of construction hydraulic structures of various purposes with minimal use of divers manual labor is set forth by the authors in this article.

Thanks to modern technology, a number of the latest designs of marine structures for various purposes have been developed and put into practice. This primarily relates to coastal protection structures and structures erected on the continental shelf for the development of offshore hydrocarbon deposits, the development of which has been carried out for many years in technically advanced countries. These types of offshore hydraulic structures are being built in the open sea, being exposed to the force of natural factors, already in the process of construction, complicating it.

Keywords: protection construction, face plate, support frame, pile, external loads.

Постановка проблемы. Морские берегозащитные сооружения, построенные в нашей стране более 30 лет тому назад, находятся либо в аварийном, либо в полностью разрушенном состояниях. Причин таких разрушений, установленных на основании анализа результатов натурных обследований, достаточно много. Наиболее существенной из них является неудовлетворительное качество работ в процессе их строительства. В первую очередь это относится к качеству бетона и технологии изготовления конструктивных элементов на заводах железобетонных изделий, а также к устройству каменных постелей и укладки на них основных конструктивных элементов берегозащитных сооружений.

Часть черноморского шельфа с разведанными запасами углеводородов, принадлежащих нашей стране, находится на умеренных глубинах воды. Обустройство таких месторождений потребует разработки и строительства морских нефтегазопромысловых гидротехнических сооружений на относительно малых глубинах воды. Их надежность в процессе эксплуатации во многом зависит от методов строительства в условиях открытого моря. По этой причине разработка эффективной технологии возведения морских гидротехнических сооружений на незащищенных акваториях представляется весьма важной инженерной задачей.

Анализ конструкций берегозащитных сооружений и способов их возведения. Общая протяженность морского побережья в нашей стране на Черном и Азовском морях составляет примерно более 1500 км. Под воздействием силового воздействия ветровых волн и дрейфующих ровных ледяных полей берега постоянно разрушаются. Особенно опасны такие разрушения для населенных пунктов, находящихся в непосредственной близости от уреза воды. Способствует интенсивному разрушению берегов и хозяйственная деятельность человека. По этой причине значительная часть берегов требует защиты специальными берегозащитными сооружениями активного и пассивного типов [1-6]. 
ВІСНИК

ОДЕСЬКОГО НАЦІОНАЛЬНОГО

МОРСЬКОГО УНІВЕРСИТЕТУ

№ 1 (61), 2020
HERALD

OF THE ODESSA NATIONAL

MARITIME UNIVERSITY № 1 (61), 2020

К сооружениям активного типа относятся, прежде всего, отмелые пляжи, буны, прерывистые вдоль береговой линии волноломы и искусственные мысы. Благодаря строительству таких сооружений удается не только стабилизировать ширину пляжей, но и наращивать их ширину.

Сооружения пассивного типа, в том числе и городские набережные, возводятся в тех случаях, когда необходимо в экстренном порядке остановить наступление моря на берега, на которых уже расположены гражданские и промышленные сооружения, а также другие исторические объекты и памятники архитектуры. Такие сооружения возводятся непосредственно в урезной зоне.

Основными конструкциями бун и волноломов, построенных в Украине, является кладка из бетонных массивов или каменная наброска. Бетонные массивы, при установке в проектное положение требуют предварительного устройства каменных постелей с весьма тщательным равнением (рис. 1).

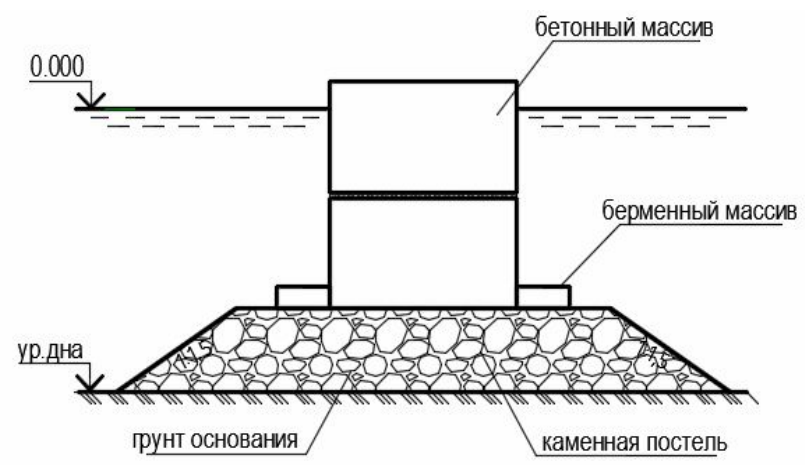

Рис. 1. Буна из бетонных массивов

Технология подводно-технических работ при их устройстве невозможна без применения непроизводительного и дорогостоящего ручного труда водолазов. Строительство постелей, в условиях открытого моря, сопряжено с целым рядом трудностей, связанных с погодными условиями (ветер и ветровое волнение), а также с использованием плавучих кранов на малых глубинах. Следует отметить, что неблагоприятные погодные условия являются главной причиной увеличения сроков строительства морских объектов на незащищенных акваториях.

Что касается строительства бун из каменной наброски, то основными трудностями при этом является доставка камня на дальние расстояния и его сортировка для защиты поверхностей откосов (рис. 2). 


\begin{tabular}{c|c} 
ВІСНИК & HERALD \\
ОДЕСЬКОГО НАЦІОНАЛЬНОГО & OF THE ODESSA NATIONAL \\
МОРСЬКОГО УНІВЕРСИТЕТУ & MARITIME UNIVERSITY \\
№ 1 (61), 2020 & № 1 (61), 2020 \\
\hline
\end{tabular}

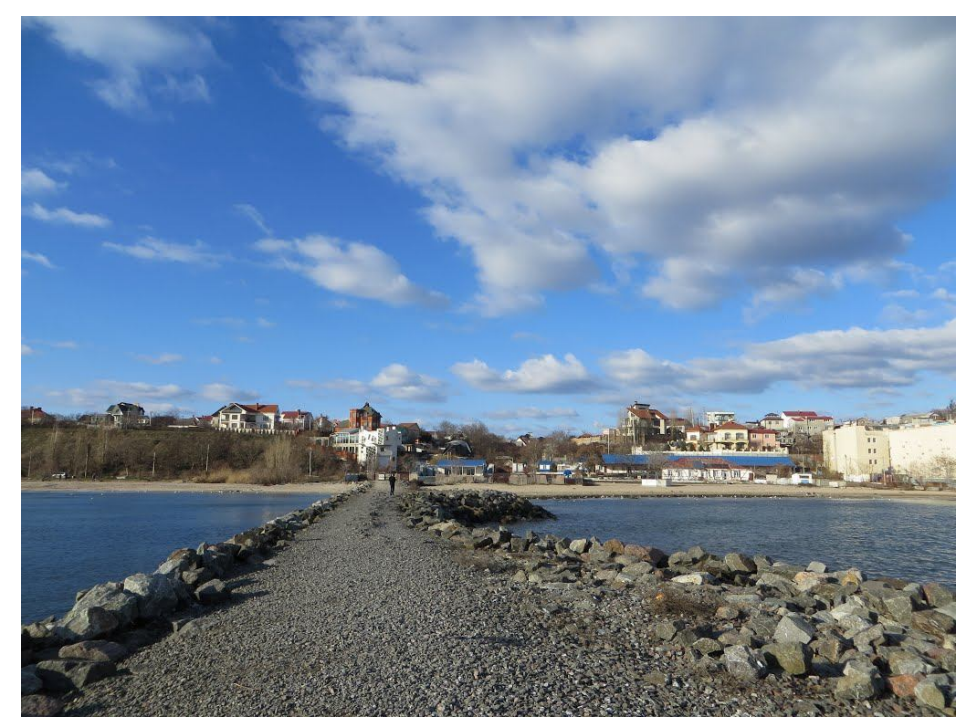

Рис. 2. Буна из каменной наброски в Крыюановке

Берегозащитные сооружения пассивного типа в нашей стране и в Одесском регионе в частности, представлены различными вертикальными или откосными конструкциями. Сооружения вертикального типа часто сочетают в себе и городские набережные и волноотбойные стенки (рис. 3).

Недостатком таких конструкций является подмыв основания, что требует их строительство в комплексе с другими сооружениями.

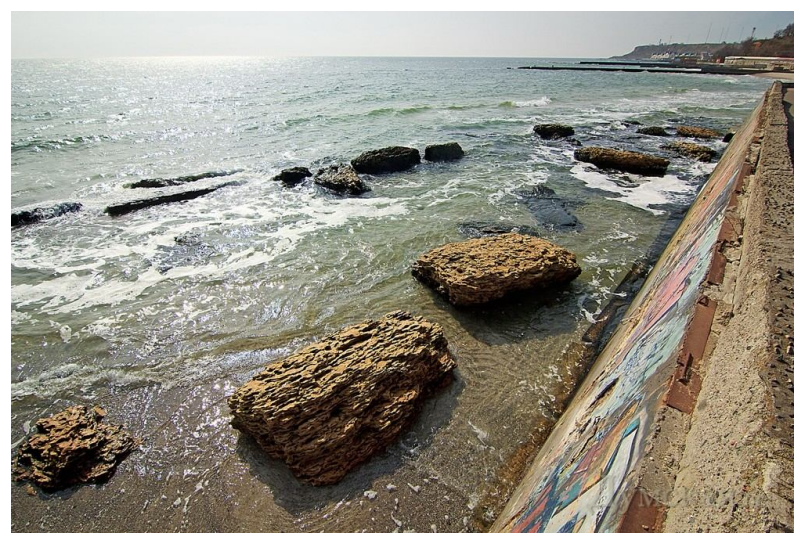

Рис. 3. Набережная 16 станцฺия Большого Фонтана

Откосы сооружений наклонного профиля защищаются либо сортированным рваным камнем, либо искусственными бетонными блоками, либо железобетонными плитами - сплошными или щелевыми (см. рис. 4). 


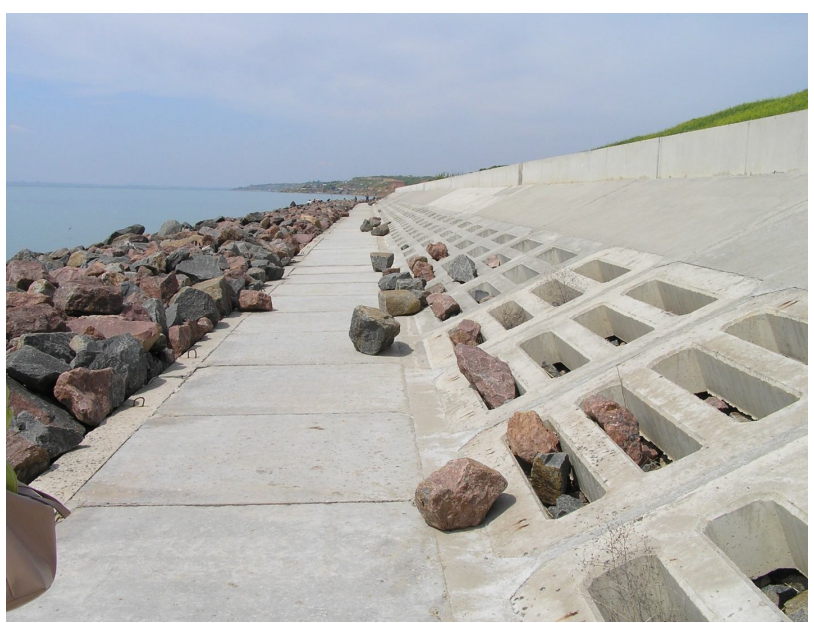

Рис. 4. Конструкиия берегозашиты мысовой формы в с. Крыжановка

В настоящее время в различных странах мира разработан целый ряд новых конструктивных решений берегозащитных сооружений [7-12], которые были построены с учетом местных гидрологических и топографических условий. Технология возведения таких сооружений довольно специфическая и сложная. По ряду климатических и гидрологических условий эти конструкции неприемлемы для условий нашей страны.

Цель и задачи исследования. Целью настоящей работы является разработка инновационного технологичного способа возведения берегозащитных сооружений пассивного типа, а также искусственных островов для обустройства морских месторождений углеводородов на мелководных участках континентального шельфа при минимальном использовании дорогостоящего и непроизводительного ручного труда водолазов. Особенностью этих типов гидротехнических сооружений является их возведение на незащищенных от воздействия ветровых волн акваториях.

Материалы исследований. Возведение всех типов берегозащитных сооружений (традиционных и инновационных) является весьма трудоемким и сложным технологическим процессом. В настоящей работе приведен новый способ возведения универсального морского гидротехнического сооружения (рис. 5), в котором из простых унифицированных элементов, изготавливаемых в заводских условиях, собирается конструкция берегозащитного сооружения пассивного типа или островного морского нефтегазопромыслового гидротехнического сооружения [13; 14].

Кроме этого, данное универсальное гидротехническое сооружение может успешно применяться и при наступлении на водоемы с целью образования новых дополнительных территорий. Использование свай и рванного несортированного камня в данной конструкции расширяет область ее применения для различного функционального назначения. 


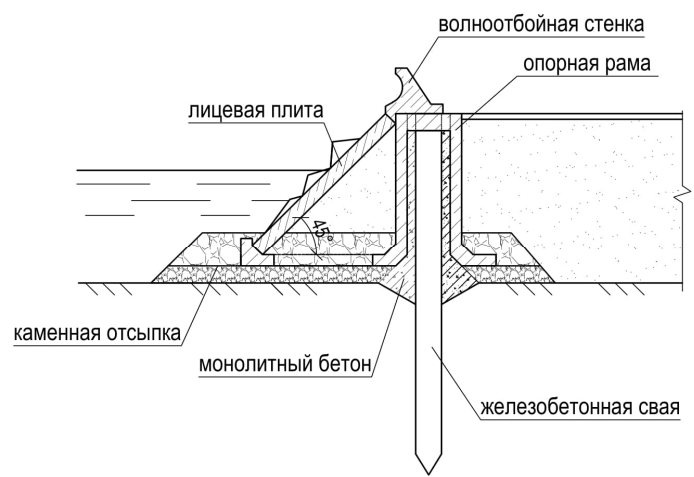

Рис. 5. Универсальное берегозащитное сооружение

Способ возведения универсального гидротехнического сооружения осуществляют следующим образом [15]. После геодезической разбивки и закрепления на местности створов, производят погружение железобетонных свай в грунт основания с определенным шагом и отсыпают первую очередь каменной засыпки под проектную отметку. Затем оголовки железобетонных свай срезают до проектной отметки и на них устанавливают опорные рамы. Затем сваи и опорные рамы омоноличивают бетоном так, что часть бетонной смеси достигает дна у сваи, образуя дополнительный донный упор. После затвердения монолитного бетона устанавливают наклонные или вертикальные лицевые плиты. Далее выполняют вторую очередь каменной засыпки, образуя банкет, и обратную засыпку. Поверху устанавливают монолитную волноотбойную стенку, разделенную по длине температурными швами.

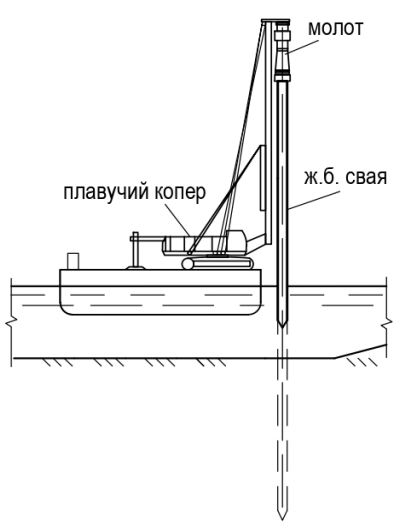

Рис. 6. Проиесс погружения свай

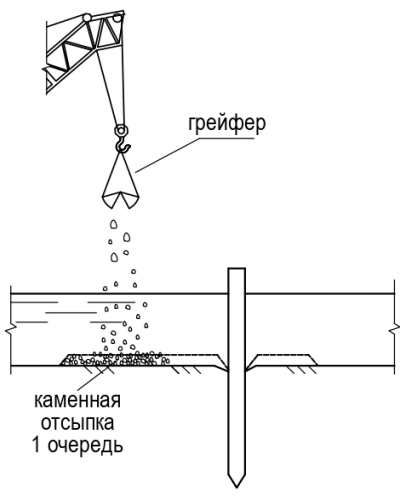

Рис. 7. Отсыпка камня в постель 


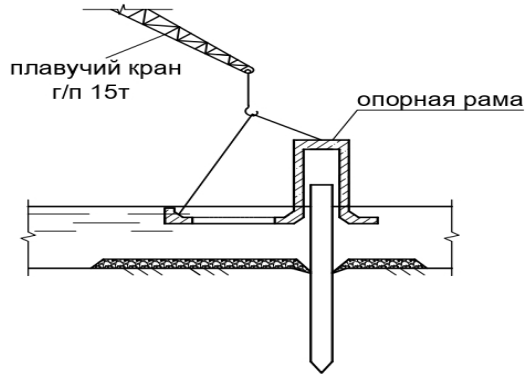

Рис. 8. Установление опорной рамь

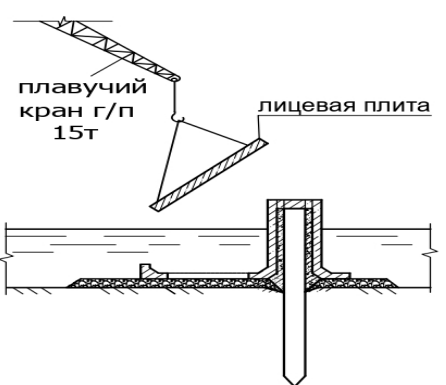

Рис. 10. Установление лицевой плить

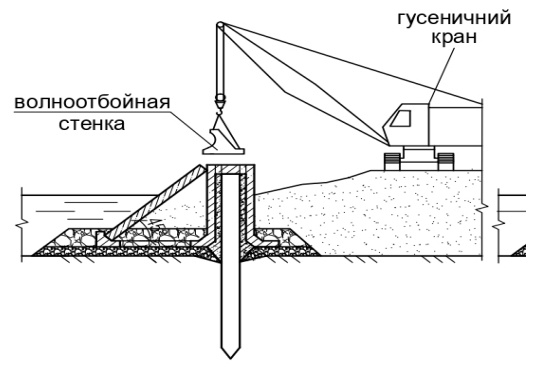

Рис. 12. Установка волноотбойной стенки

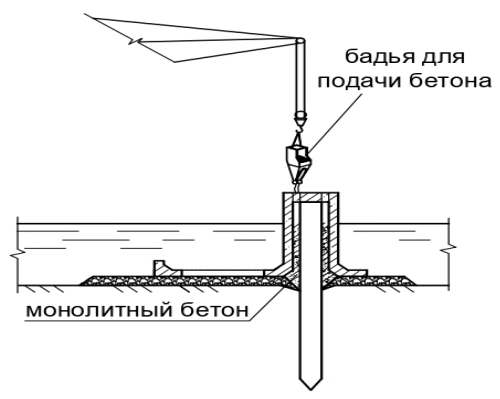

Рис. 9. Омоноличивание

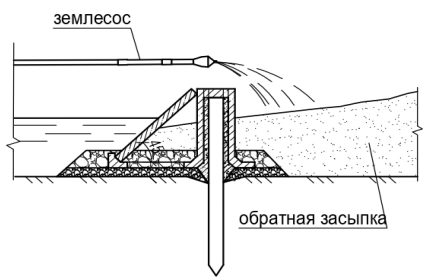

Рис. 11. Рефулирование обратной засыпки

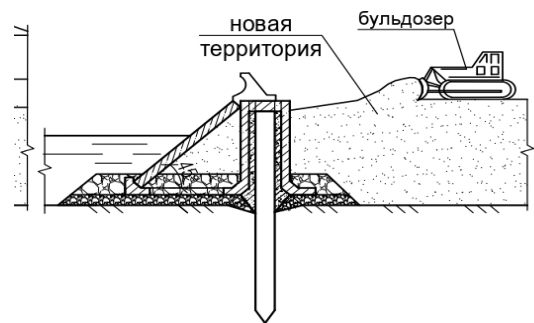

Рис. 13. Планировка искусственной территории или острова

Возведение данной конструкции не требует производства подводно-технических работ по подготовке основания под сооружением. Данный тип сооружений может возводиться на грунтах, допускающих забивку свай. Берегозащитное сооружение монтируется из сборных унифицированных элементов, что позволяет увеличить темпы строительства. Оно может легко восстанавливаться после локальных повреждений жесткими штормами или дрейфующими ледовыми образованиями. Конструкция мало чувствительна к подмыву основания течениями и волновыми скоростями. 
ВІСНИК

ОДЕСЬКОГО НАЦІОНАЛЬНОГО

МОРСЬКОГО УНІВЕРСИТЕТУ

№ 1 (61), 2020
HERALD

OF THE ODESSA NATIONAL

MARITIME UNIVERSITY № 1 (61), 2020

\section{Выводы}

1. Данный способ возведения универсального гидротехнического сооружения в условиях открытого моря обеспечивает снижение сроков строительства благодаря своей простоте.

2. Реализация данного способа не требует проведения специальных подводно-технических работ по подготовке грунтового основания под сооружение.

3. Каменный банкет перед сооружением одновременно выполняет роль контрфильтра и защиты грунтового основания от размывов течениями и волновыми скоростями.

4. В зависимости от функционального предназначения и природных условий в месте возведения, лицевые плиты могут быть вертикальными, наклонными или криволинейными.

5. Способ возведения универсального гидротехнического сооружения такой конструкции можно использовать при: укреплении берегов; создании дополнительных территорий в прибрежных зонах морей, озер, водохранилищ и лиманов, в том числе и искусственных островов; для обустройства месторождений углеводородов на мелководных участках континентального шельфа Черного моря, принадлежащего нашей стране.

6. Реализация данного способа не требует создания специальной производственной береговой базы, поскольку конструктивные элементы инновационного сооружения изготавливаются на заводах железобетонных сооружений.

7. Конструктивные элементы сооружения и рваный камень могут доставляться к месту строительства водным транспортом. Для этой цели могут использоваться причалы портофлота ближайшего к месту строительства порта.

\section{СПИСОК ЛІТЕРАТУРИ}

1. Рогачко С.И. Защита побережья у Белгород-Днестровской крепости [Текст]/ С.И. Рогачко, Е.В. Чикина // Вісник Одеської державної академії будівництва та архітектури. Одеса: ОДАБА, 2015. № 58. С.330-333.

2. Рогачко С.И. Особенности проектирования морских берегозащитных сооружений [Текст]/ С.И. Рогачко, В.Г. Бааджи // Будівельні конструкиї: Міжн. наук.-техн. зб. Bun.83, книга 2. Київ, ДП НДІБК, 2016. С.282-287. 
3. Обзор методов берегозащить на Черноморском побережье России [Электронный ресурс]. Режим доступа до ресурсу: http://arch-sochi.ru/2012/10/obzor-metodov-beregozashhityi-nachernomorskom-poberezhe-rossiil

4. Смирнова Т.Г. Берегозащитные сооружения / Т.Г. Смирнова, Ю.П. Правдивеи, Г.Н. Смирнов. М.: Изд-во АСВ, 2002. 303 с.

5. Шуйский Ю.Д. Опыт анализа берегозащитных сооружений на песчаных берегах Черного моря [Текст] / Ю.Д. Шуйский, Р.П. Перейрас // Строительство и техногенная безопасность. 2011. № 39. C.110-116.

6. Шуйский Ю.Д. Развитие берегозащитных сооружений на берегу Черного моря в пределах Одессы [Текст] / Ю.Д. Шуйский // Причерноморский Экологический бюллетень. 2010. № 4 (38). C. 45-79.

7. EunChul Shin, Sung Hwan Kim, Abdul Hakat and Bambang Istijono. Erosion problems of shore line and counter measurement by various geomaterials. MATEC Web Conf. Volume 265, 2019. International Geotechnical Symposium «Geotechnical Construction of Civil Engineering \& Transport Structures of the Asian-Pacific Region» (GCCETS 2018). https://doi.org/10.1051/ matecconf/ 201926501010.

8. Paolo Alfredini, Emilia Arasaki, J.C.M. Bernardino, Gabriela da Silva. Alternative study for the Nautical and Shore Protection Structures in the Estuary of Santos, Brazil. TransNav: International Journal on Marine Navigation and Safety of Sea Transportation. 2018;12(2):375-380 DOI 10.12716/1001.12.02.19.

9. Thomas J.F. Goreau, Paulus Prong. Biorock Electric Reefs Grow Back Severely Eroded Beaches in Months. Journal of Marine Science and Engineering. 2017; 5(4):48. DOI 10.3390/jmse5040048.

10. Amit Srivastava, G. L. Sivakumarbabu. Analysis and design of reinforced earth wall for shore protection system against tsunami. Science of Tsunami Hazards. 2009;28(3):186-204.

11. Hans J. Scheel. Novel tsunami barriers and their applications for hydroelectric energy storage, fish farming, and for land reclamation. Science of Tsunami Hazards. 2014; 33(3):170-192.

12. Scheel H.J. (2014a). New type of tsunami barrier, Natural Hazards, 70, 951-95.

13. Патент на корисну модель № 113315. Украӥна. МПК(2006.01) E02B 3/04. Берегозахисна споруда / Рогачко C.I., Слободяник Г.В.; винахідники та власники Рогачко С.І., Слободяник Г.В.; № 201607059; Заяв. 29.06.2016; Публ. 25.01.2017. Бюл. № 2. $4 c$. 
14. Рогачко С.И. Универсальное гидротехническое сооружение [Текст] / С.И. Рогачко, А.В. Слободяник, О.В. Казмирук // Вісник Одеської державної академї будівництва та архітектури. Одеса: ОДАБА, 2017. № 67. С.115-120.

15. Патент на корисну модель № 117078. Україна. МПК(2006.01) E02B 3/06. Спосіб зведення берегозахисної споруди / Рогачко С.I., Казмірук О.В., СлободяникГ.В.; винахідник та власник Рогачко С.I., Казмірук О.В., Слободяник Г.В.; № 201700702; Заяв. 25.01.2017; Публ. 12.06.2017, Бюл. № 11 . $5 c$.

\section{REFERENCES}

1. Rogachko S.I., Chikina E. V. Coastal protection at the BelgorodDniester fortress (2015) News of Odessa State Academy of Civil Engineering and Architecture, 58, 330-333.

2. Rogachko S.I., Baaji V.G.(2016) Design features of marine coastal protection structures. Budivelnye konstrukcii: Mízhvídomchiy naukovo-tekhnichniy zbirnik. Vip. 83, book 2. Kiev, DP NDIBK, 2016. P. 282-287.

3. Obzor metodov beregozashchity na Chernomorskom poberezh'ye Rossii. Retrieved from http://arch-sochi.ru/2012/10/obzor-metodovberegozashhityi-na-chernomorskom-poberezhe-rossii.

4. Smirnova, T.G.. Pravdivets, YU.P., Smirnov, G.N.(2002). Beregozashchitnyye sooruzheniya. Moskva ASV (in Russian).

5. 5. Shuyskiy, YU.D., Pereyras, R. P. (2011). Opyt analiza beregozashchitnykh sooruzheniy na peschanykh beregakh Chernogo moray. Stroitel'stvo i tekhnogennaya bezopasnost', 39, 110-116.

6. Shuyskiy YU.D. (2010). Razvitiye beregozashchitnykh sooruzheniy na beregu Chernogo morya $v$ predelakh Odessy. Prichernomorskiy Ekologicheskiy byulleten', 4, 45-79.

7. EunChul Shin, Sung Hwan Kim, Abdul Hakat and Bambang Istijono. (2019). Erosion problems of shore line and counter measurement by various geomaterials. Retrieved from https://doi.org/ 10.1051/ matecconf/201926501010.

8. Paolo Alfredini, Emilia Arasaki, J.C.M. Bernardino, Gabriela da Silva (2018) Alternative study for the Nautical and Shore Protection Structures in the Estuary of Santos, Brazil. 12(2):375380.

9. Thomas J.F. Goreau, Paulus Prong (2017) Biorock Electric Reefs Grow Back Severely Eroded Beaches in Months. Journal of Marine Science and Engineering. 5(4):48. 
ВІСНИК

ОДЕСЬКОГО НАЦІОНАЛЬНОГО

МОРСЬКОГО УНІВЕРСИТЕТУ

№ 1 (61), 2020
HERALD

OF THE ODESSA NATIONAL

MARITIME UNIVERSITY

№ 1 (61), 2020

10. Amit Srivastava, G. L. Sivakumarbabu (2009) Analysis and design of reinforced earth wall for shore protection system against tsunami. Science of Tsunami Hazards. 28(3):186-204.

11. Hans J. Scheel. (2014). Novel tsunami barriers and their applications for hydroelectric energy storage, fish farming, and for land reclamation. Science of Tsunami Hazards. 33(3):170-192.

12. Scheel H.J. (2014a). New type of tsunami barrier, Natural Hazards, 70, 951-95.

13. Patent for utility model № 113315. UKRAINE. MPK(2006.01) E02B 3/04. Coast guard construction / S.I. Rogachko, G.V. Slobodyanik; inventor and owner S.I. Rogachko, G.V. Slobodyanik; №201607059; Said. 29.06.2016; Vid. 25.01.2017, Bull. № 2, 4 . .

14. Rogachko, S.I., Slobodyanik, A.V., Kazmiruk O.V. (2017) Universal hydrotechical structure. News of Odessa State Academy of Civil Engineering and Architecture, 67, 115.

15. Patent for utility model № 117078. UKRAINE. MPK(2006.01) E02B 3/06. A method of erecting a coastal protection structure / S.I. Rogachko, G.V. Slobodyanik, O. V. Kazmiryk; inventor and owner S.I. Rogachko, G.V. Slobodyanik, O.V. Kazmiryk; № 201700702; Said. 25.01.2017; Vid. 12.06.2017, Bull. № 11, 5 p.

Стаття надійшла до редакиії 12.03.20

Посилання на статтю: Рогачко С.И., Слободяник А.В. Способ возведения универсального морского гидротехнического сооружения // Вісник Одеського національного морського університету: Зб. наук. праць, 2020. № 1(61). C. 167-179. DOI 10.47049/2226-1893-2020-1-167-179.

Article received 12.03.20

Reference a Journal Artic: Rogachko, S., Slobodianyk, H. The method of construction of an universal marine hydraulic structures. 1(61), 167-179 // Herald of the Odessa national maritime university. DOI 10.47049/2226-1893-2020-1-167-179. 